\title{
Editorial
}

\section{ELIP 2021: Expanding Possibilities for Community}

As I reflect on the past year in order to write this editorial, I was struck by how much my first year in the MLIS program has been shaped by ELIP's production process. Having started the program online last fall, I was worried about being unable to connect with the wonderful FIMS community. After all, like almost everyone I have met during the MLIS program, I was drawn to this work due to an interest in community building. I am very grateful to have had the opportunity to expand my imagination and capacity for community building while moving our entire publication cycle online as a result of the pandemic. We conducted workshops, office hours, and class visits through Zoom. We would have hosted several events at the FIMS Graduate Library in previous years, which was obviously not possible this time around. (Though I did appreciate the opportunity to stop by the FIMS Graduate Library a few times!) Still, I learnt about our contributors' lives and writing styles, whether through meetings, cover photo submissions, or comments in the Word documents we passed back and forth. We were able to move the entire process online because ELIP's strength is the wonderful people whose labour makes this journal possible. I am very grateful for this team, and want to emphasise how impossible this publication cycle would have been without them. Thank you to our authors for trusting us with sharing your writing and to our Editorial Team Advisors and Editorial Advisory Board members for reviewing submissions and working with authors. Thank you also to our volunteers for contributing all the labour necessary to actualise our authors' vision. A special thank you goes out to Marni Harrington and Melissa Seelye for their guidance throughout this year.

The range of topics represented in the five articles, three For the Field, two In the Field, interview and review essays is wide. Our articles touch on learning analytics and information ethics, the impact of the COVID-19 pandemic on public libraries, Indigenous knowledges and bibliographic description, archival description and organization, Disability studies and subject indexing, and informed consent in social media research. The flexibility of length and format, as well as the possibility for collaboration, means that we have something for every reader!

Advocacy was a prominent theme, as some authors wrestled with the moral responsibilities we have to our patrons. Two authors analysed cataloguing and indexing standards: Amelia Hunter thoughtfully demonstrates the marginalisation of Indigenous Peoples in the creation of metadata and issues a 
call to action for fellow settler librarians in the spirit of truth and reconciliation; Carolyn Sullivan traces the evolution of the language used to describe disability and disabled people in the Library of Congress Subject Headings. Our In the Field submissions explored two underresourced and unique areas of library practice, corrections and makerspaces librarianship. Erica McKenzie describes her experience creating the books to prison initiative Beyond the Sentence, offering suggestions for how we can join this important work. Highlighting the necessity of properly valuing and compensating library professionals' labour in a similar vein, Dalia Levy argues passionately against the creep of commodification in public library makerspaces.

Additionally, several authors considered how we can most effectively and ethically meet our patrons' needs. Magnus Berg's article explores how archivists can tailor multi-level description to meet the needs of online archival database users. The ethics of data collection was another prominent theme: Chad Currier enumerates the privacy concerns in the collection of analytics by higher education institutions, while Kate McCandless describes the debate about creating new ethical standards for the collection of data for social media research.

As the name of our journal suggests, the emerging situation of the pandemic is reflected in several papers, including Nelson Rosales' For the Field piece surveying the response of public libraries to the COVID-19 pandemic and Sophia Grande Lawlor's interview with Lauren Bourdages about the essential role played by library reserve teams in the last year. Veronica Berry, Sara Clarke, Sandra Moore and Kevin Oswald's discuss their takeaways from the co-op experience at Western Libraries and share how the pandemic impacted their positions.

Other pieces offer suggestions for library programming. Carlie Forsythe provides helpful tips and tricks for library professionals interested in starting their own board game collections. Kate McCandless makes a compelling case for the inclusion of Wikipedia edit-a-thon events in library programming. Last, but not least, Carolyn Sullivan's review of Megan Rosenbloom's Dark Archives about the history of anthropodermic bibliopegy, or the binding of books in human skin, is perfect for readers who are curious about the subject or looking to read outside their comfort zone.

I am going to miss organising the chaotic, colour coded file on my desktop where this edition has lived in its multiple iterations over the last few months, but I am so excited we can share it with you all now. Our submissions chronicle this moment and chart futures for our profession. While the forces of capital, racism, and colonialism seem insurmountable right now, in abolitionist organizer and MLIS candidate Mariame Kaba's words, "Hope is a discipline." I hope these 
reflections on professional practice and the history of library and information science help you consider what you can do everyday to cultivate a practice of hope and change in our workplaces and world.

-Aarushi Mohan, Managing Editor

\section{Aarushi Mohan}

Mohan, A. (2021). ELIP 2021: Expanding possibilities for community. Emerging Library \& Information Perspectives, 4, 2-4. https://doi.org/10.5206/elip.v4i1.14073

\section{Reference}

Wilson, K. and Sonenstein, B. (2018, January 5). Mariame Kaba. [Audio podcast episode]. In Beyond Prisons. https://www.beyond-prisons.com/home/hope-is-adiscipline-feat-mariame-kaba

\section{Land Acknowledgement}

The FIMS Graduate Library is situated on the traditional lands of the Anishinaabek, Haudenosaunee, Lūnaapéewak and Attawandaron peoples. Taking a page from the land acknowledgement written by the middle schoolers at the Lillian Berg Public School created after reading Indigenous author David A. Robertson's book Barren Grounds:

We are grateful for how the land helps beautiful trees grow, which both bring us joy and gives shelter to birds and squirrels. We are grateful for how the land holds rainwater, allowing water to move through our world. We are grateful for the food that is grown (mostly by migrant workers) in the earth that nourishes and sustains us. We are grateful for the walks we take on the land that give us respite during these times of reduced social interaction during the pandemic.

We honour the land and believe in their return to their original Indigenous stewards. We encourage you to act to support demands for Land Back and Indigenous sovereignty. Here are some starting points:

-Guide your learning with Biindigen's Indigenous History Month Challenge.

-Support the Indian Residential School Survivor Society.

-For people in London, Ontario, take these actions compiled by Jenna Rose Sands, a Nehiyaw and Anishinaabek visual artist, writer and activist from the Bkejwanong First Nation. 